\title{
EPITOME OF CURRENT JOURNALS
}

\section{AMERICAN JOURNAL OF PSYCHIATRY}

Vol. 98.

The Military Psychiatrist at Work. W. C. Porter. 317.

The Clinical Differentiation of Senile and Arteriosclerotic Psychoses. D. Rothschild. 324.

Narcolepsy. W. F. Murphy. 334.

Encephalopathia Alcoholica. N. Joliffe and H. Wortis. 340.

The Incidence and Significance of Alcoholism in the History of Criminals. M. G. Gray and M. Moore. 347.

Brain Metabolism, VIII. The Effects of Electric Shock and Some Newer Drugs. S. B. Wortis, D. Shaskan, D. Impastato, and R. Almansi. 354 Prognostic Criteria in Schizophrenia. L. S. Chase and S. Silverman. 360 .

Insulin Convulsions. A Method of Prevention. J. P. Frostig, C. R. Bennett, J. Schreiber, and G. F. Thomas. 369.

Encephalography in Schizophrenia. K. H. Finley and C. M. Campbell. 374.

Follow-Up Results in Insulin Shock Therapy after One to Three Years. T. D. Rivers and E. D. Bond. 382.

Electroencephalographic Studies of Corticohypothalamic Relations in Schizophrenia. R. B. Grinker and H. M. Serola. 385 .

The Vitamin $B_{1}$ Requirement during Insulin Shock Therapy. W. Goldfarb and K. M. Bowman. 3i)3.

The Treatment of Childhood Schizophrenia by
No. 3.

November 1941.

Metrazol Shock Modified by B-Erythoidin. F. Cottington. 397.

The Effect of Convulsive Treatment on Memory I. Sherman, J. Mergener, and D. Levitin. 401. Electroencephalographic Studies in Organic Psychoses. P. Hoch and J. Kubis. 404.

Studies on the Corpus Callosum, VIII. The Effects of Partial and Complete Section of the Corpus Callosum of Psychopathic Epileptics. A. J. E. Akelaitis. 409.

Experiences with a New Criminal Code in New York State. B. Apfelberg. 415.

Parallel Psychological, Psychiatric, and Physiological Findings in Schizophrenic Patients under Insulin Shock Treatment. B. H. McNeel, J. G. Dewan, C. R. Myers, L. D. Proctor, and J. E. Goodwin.

Electroencephalograms of Manic-Depressive Patients. P. A. Davis. 430.

Evaluation of the Results of Psychoanalytic Therapy R. P. Knight. 434.

Mental Disorder in One of a Pair of Identical Twins. G. E. Hobbs. 447.

Psychiatric Observations on Children with $\mathrm{Ab}$ dominal Pain. J. P. Lambert. 451.

Ordinal Position and Schizophrenia. R. M. Patterson and T. W. Zeigler. 455.

Disorganizing Factors of Infant Personality. M. A. Ribble. 459.

\section{ARCHIVES OF NEUROLOGY AND PSYCHIATRY, CHICAGO}

Vol. 46.

*Objective Measurement of Relative Intracranial Blood Flow in Man, with Observations concerning the Hydrodynamics of the Craniovertebral System. E. B. Ferris. 377.

*Corpus Striatum and Thalamus of a Partially De corticate Monkey. S. W. Ranson, S. W. Ranson, corticate Monkey. S. W. Ra

Junr., and M. Ranson. 402. Subcortical Hematoma: Surgical Treatment, with Report of Eight Cases. C. Pilcher. 416.

*Hepatolenticular Degeneration: Report of a Case. C. G. Babcock and H. W. Brosin. 431 .

Multiple Meningioma: Removal of Ten Intracranial Tumors from a Patient. D. H. Echols. 440.

Vascular Malformations and Vascular Tumors involving the Spinal Cord: A Pathologic Study of volving the Spinal Cord: A Pathologic Study of Forty-Six Cas

*Peripheral Neuropathy: Evaluation of Sensory Findings. M. H. Stein, H. Wortis, and N. Joliffe. 464.

*Tabes Dorsalis: Evaluation of the Sensory Findings. M. H. Stein and H. Wortis. 471.

*Changes in the Brain in Pertussis with Convulsions. V. B. Dolgopol. 477.

* Observations on Monkeys with Bilateral Lesions of the Globus Pallidus. S. W. Ranson and C. Berry. 504.

*Intracranial Blood Flow in Insulin Coma. E. B. Ferris, M. Rosenbaum, C. D. Aring, H. W. Ryder, E. Roseman, and J. R. Hawkins. 509.

Objective Measurement of Intracranial Blood Flow.-For the objective measurement of a function of total intracranial
No. 3.

September 1942.

blood flow in man, a method was devised which in its basic principle resembled that used to study the blood flow to extremities by the venous occlusion plethysmographic method. The values obtained appear to be of the same order of magnitude as the actual volume flow of blood through the cranium. It is estimated that the total intracranial blood flow of normal man does not exceed levels of 250 to 400 c.c. per minute under the conditions of these experiments. (R.M.S.)

Corpus Striatum and Thalamus.-A study of the fibre connections of the corpus striatum and thalamus of a partially decorticate monkey. (R. M. S.)

Subcortical Hæmatoma.-Eight cases of solitary subcortical hæmatoma, in all of which the patients were subjected to surgical therapy, are reported. In three cases hæmorrhage was of traumatic origin, in four it was spontaneous, and in the eighth the case was doubtful. The ages of the patients varied from 5 to 62 years, but six patients were under 40 . In six cases the 
location was temporal or parietal, in one frontal and in one cerebellar. There were no operative deaths, but two of the patients died six and nine months later, respectively: one of pneumonia and one of unknown cause. The symptomatology, diagnosis, pathology, operative treatment, and surgical results are discussed. (R. M. S.)

Hepatolenticular Degeneration.-A case of hepatolenticular degeneration is described with emphasis on the mental status of the patient, and the absence of tremor at the time the diagnosis was made. With the usual methods of testing hepatic function (van den Bergh, bilirubin excretion and bromsulphalein tests), no abnormality was found, but the patient was found to have prothrombin deficiency, a condition which may be interpreted as indicative of hepatic damage. (R. M. S.)

Peripheral Neuropathy.--Sensory dissociation is a characteristic feature of the peripheral neuropathy complicating alcoholism and other conditions associated with disturbed nutrition. Light touch, vibration, and position senses and " first" pain sense are affected earliest and most severely. These sensations are carried by the large, myelinated A and B fibres, which are affected earliest and most severely in such conditions. "Second" pain sense, which is conveyed along the slow, unmyelinated $\mathrm{C}$ fibres, is spared. Immediate dysesthesia represents a stage of injury of the peripheral nerve at which some of the myelinated (A and B) fibres are still functioning, while others have been blocked. Delayed dysesthesia represents the stage at which practically all of the myelinated (A and $B$ ) fibres have been blocked, only small, unmyelinated fibres continuing to function. The delay in perception results from the very slow transmission along the $C$ fibres. The sensory dissociation and dysesthesia of peripheral neuropathy may be duplicated experimentally by producing ischemia of an extremity. As the ischemia progresses, the loss of function of the peripheral nerve becomes more severe and the dysesthesia changes from the immediate to the delayed type. In peripheral neuropathy of this type, the large, myelinated ( $\mathrm{A}$ and $\mathrm{B}$ ) fibres are primarily affected. This indicates that these fibres have greater metabolic needs, and are therefore most susceptible to nutritional deficiency. (R. M. S.)

Tabes Dorsalis.-Sensory dissociation and dysesthesia were noted in 18 patients with tabes dorsalis. In 11 of these patients the dysesthesia was delayed, and in each of these there was marked delay in pain perception. The delay in pain perception and the dysesthesia have been related to blocking of fast conducting impulses, allowing more slowly conducted impulses to be perceived at a later time and in uninhibited fashion. It is suggested that the physiological mechanism of the delayed pain perception and dysesthesia associated with tabes dorsalis is analogous to that previously noted with disorders of the peripheral nerve. (R. M. S.)

Brain Changes in Pertussis.-The changes in the brain in pertussis are apparently noninfectious. They are most likely of circulatory origin and consist in oedema, ischemic cellular degeneration. multiple hæmorrhages (usually small) and lymphocytic plugs in veins and capillaries. On rare occasions a secondary "Encephalitic reaction " may be observed in addition to the aforementioned changes. (R. M. S.)

Bilateral Lesions of Globus Pallidus.Three monkeys with large bilateral lesions in the globus pallidus showed none of the signs which point to striatal disease in man. None of the animals showed cogwheel resistance to passive movement; none had any trace of a Parkinsonian tremor. Choreiform and athetoid movements did not occur. The animals did not have the typical mask-like face and slowness of movement characteristic of paralysis agitans. The question is raised whether damage to the hypothalamus may not play a part in producing the Parkinsonian syndrome in man. (R. M. S.)

Intracranial Blood Flow in Insulin Coma. - The authors conclude from their studies that hypoglycemia coma, induced by the administration of insulin, is associated with either no change or a slight increase in total intracranial blood flow. (R. M. S.)
Vol. 46

*The Wernicke Syndrome. N. Joliffe, H. Wortis, and H. D. Fein. 569.

The Electroencephalogram as an Aid in the Study The Electroencephalogram as an Aid in the Study
of Narcolepsy. J. B. Dynes and K. H. Finley. 598.

*The Cortical Frequency Spectrum in Epilepsy. F. A. Gibbs, W. G. Lennox, and E. L. Gibbs. 613 . *Cutaneous Pressure-Vibration Spots and their Underlying Tissues. B. v. H. Gilmer and S. R. Haythorn. 621.

*Effect of Nicotinic Acid and Related Substances on the Intracranial Blood Flow of Man. C. D. Aring, H. W. Ryder, E. Roseman, M. Rosenbaum Aring, H. W. Ryder, E.

* Muscular Shortening and Dystrophy. A HeredoMuscular Shortening and Dystrophy. A HeredoThannhauser. 654 .
No. 4.

October $194 !$.

*Characteristics of After-Discharge following Cortical Stimulation in the Monkey. M. R. Sapirstein. 665 .

*Anticonvulsive Action of Azosulamide in Patients with Epilepsy. M. H. Cohen and S. Cobb. 676. Physiology of the Spinal Cord: I. Role of the Anterior Column in Hyperreflexia. O. R. Hyndman. 695.

*Cerebral Arteriography: Its Place in Neurologic Diagnosis. S. W. Gross. 704.

Wernicke Syndrome.-Twenty-seven cases of Wernicke's syndrome (three of which occurred in non-alcoholic patients) are analysed and the following conclusions 
reached. The syndrome as originally described by Wernicke is probably a combination of several nutritional deficiencies affecting the nervous system and need not necessarily be complete in any case. The authors' results indicate that (a) the ophthalmoplegia is a thiamine deficiency; (b) the clouding of consciousness may be related to anything which interferes with proper cerebral metabolism, some of the known offenders being lack of carbohydrate, lack of oxygen, lack of thiamine or nicotinic acid or riboflavin or of all three, and probably a lack of many other substances now under investigation; and (c) the ataxia is difficult to evaluate and its response to therapy has not as yet been worked out. Other deficiency syndromes may and do superimpose themselves on the more usual Wernicke picture, and these require specific treatment. The ophthalmoplegia is invariably preceded or accompanied by peripheral neuropathy. Delirium, with its marked increase in psychomotor activity, and hence in total metabolism, frequently precedes the development of this syndrome. In the recovered patients, the development of a Korsakoff syndrome is the rule. This does not show a consistent response to thiamine hydrochloride, as has frequently been claimed. (R. M. S.)

Cortical Frequency Spectrum in Epilepsy. - The Grass method of frequency analysis has been used to obtain the cortical frequency spectrums of epileptic patients, of the parents of epileptic patients, and of normal persons. Study of records made during seizures discloses the following: (a) In petit mal attacks a disproportionately high peak appears in the 2 to 3 per second region; (b) in a psychomotor seizure an abnormally high peak appears in the 4 to 7 per second region; and (c) in grand mal attacks an abnormally high peak is evident in the 20 to 29 per second region. The average spectrums of epileptic patients made in the intervals between seizures disclose a disproportionately large amount of energy at frequencies below 9 per second. However, the subgroup of patients subject only to grand mal have an abnormally great amount of energy in the 20 to 29 per second region. Patients having periodic grand mal attacks show an increase in energy in the faster frequencies as the day or the hour of the convulsion approaches. The average spectrums of a group of parents of epileptic patients show abnormalities similar to those seen in the average spectrums of epileptic patients, but these abnormalities are less extreme. (R. M. S.)

Cutaneous Pressure-Vibration Spots.Excision studies failed to substantiate the conventional claim that the cutaneous pressure qualities are mediated by specific sense receptors, since the sites for study were selected with extreme care and no such receptors were found. The possibility that the neurovascular system of the skin operates either in a direct or in an indirect manner in the mediation of cutaneous pressure and vibration is suggested by two observations. (a) The neurovascular system of the skin contains certain structural units richly endowed with a nerve supply, surrounded by regions of less nerve concentration. (b) Biopsy specimens taken from the cutaneous areas highly sensitive to pressure and vibratory stimulation were found to contain a richer afferent arterial nerve supply than the specimens taken as controls in which the tissue was less sensitive to pressure and vibration. The presence in several of the biopsy specimens from spots sensitive to pressure and vibration of certain tubular, straight canals having muscular walls which appeared to unite the glomus bodies of the stratum subcutaneum with the capillary zone of the stratum papillare and the presence of its rich reticular nerve supply served to strengthen the authors' belief that the arteriovenous anastomoses in the skin are in some way related to sensory interpretations. (R. M. S.)

Nicotinic Acid and Intracranial Blood Flow.-Nicotinic acid and quinine nicotinate administered intravenously increase the intracranial blood flow for periods lasting from 20 to 60 minutes. This effect, which parallels the flushing of the skin, diminishes gradually after the height of the reaction, which occurs within several minutes of the injection. Nicotinic acid amide has no significant effect on the total intracranial blood flow; neither does it cause flushing of the skin. (R. M. S.)

Muscular Shortening and Dystrophy.-A hereditary familial disease has been described. It is characterized by a short, "webbed" neck as well as by shortness of the neck muscles, long dorsal muscles, and flexor muscles of the upper portions of the arms. This shortness prevents the complete bending of the neck and back, as well as the stretching of the arms. There are also underdevelopment and weakness of the proximal muscles of the arms and the gluteal muscles. Decrease in or absence of deep reflexes was found in some members of the family. The webbing, which is formed by the shortened trapezius muscle, causes the neck to appear broader than usual. The cervical portion of the spinal column was normal. Roentgen examination revealed that all the vertebræ were present. The outstanding symptom of this disease is the shortening of certain muscles. In some cases, some features of progressive muscular dystrophy were present. However, most of the members of this family exhibited mainly shortening and underdevelopment of some muscles. The authors, therefore, believe that this heredofamilial anomaly is a special type of heredofamilial muscular disease. (R.M.S.)

After-Discharge following Cortical Stimu- 
lation.-A report of a study of tonic and clonic after-discharges following cortical stimulation in monkeys, both before and after cortical and subcortical ablations. (R. M. S.)

Anticonvulsive Action of Azosulfamide.The red dye azosulfamide is shown to have anticonvulsive action in some patients with epilepsy. No serious toxic effects were encountered. (R. M. S.)

Cerebral Arteriography.-Cerebral arteri- ography is indicated for the detection and localization of intracranial aneurysms, especially in recurring attacks of "spontaneous" subarachnoid hæmorrhage. It is also indicated for the localization of intracranial arteriovenous fistulas, varices, vascular tumours and vascular malformations, for the differentiation of aneurysm and tumour and for the localization of neoplasms when the result of pneumoencephalographic examination is not conclusive. (R. M. S.)

\section{Vol. 46.}

*Vascular Supply of the Spinal Ganglia. L. Bergmann and L. Alexander. 761 .

* Pathology of Amyotrophic Lateral Sclerosis: Fiber Pathology of Amyotrophic Lateral Sclerosis: Fiber Analysis of the Ventral Roots and Pyrimidal Tracts
of the Spinal Cord. G. Wohlfart and R. L. Swank. 783 .

*Studies in Diseases of Muscle: X. Prostigmine and Physostigmine in the Treatment of Myasthenia Gravis. A. T. Milorhat, with the technical assistance of W. E. Bartels. 800 .

*Neurologic Symptoms following Extensive Occlusion of the Common or Internal Carotid Artery. A. B. King and O. R. Langworthy. 835 .

*A New Method for Treatment of Cystic Craniopharyngioma by Intraventricular Drainage. J. E. Scarff. 843

*Roentgenologic Changes in the Bones in Cases of Pseudohypertrophic Muscular Dystrophy. B. S. Epstein and J. L. Abramson. 868.

*Topical Arrangement within the Spinothalamic Tract of the Monkey. T. A. Weaver and A. E. Tract of the

Metrazol Convulsions in the Treatment of the Psychosis of Dementia Paralytica. V. B. Kenyon, M. Lozoff, and D. Rapaport. 884.

Dilatin Hyperplastic Gingivitis: Its Treatment and Prevention. D. E. Ziskin, L. R. Stowe, and E. V. Zegarelli. 897.

* Removal of Tumor Arising Anterior to the Medulla. A. Ecker. 908.

Vascular Supply of Spinal Ganglia.-Most of the vessels supplying the spinal ganglion originate from the main vascular trunk (the spinal arterial branch) at right angles or by way of recurving arcs, arising off and frequently against the direction of the blood flow in the mother branch. This explains the fact that higher pressure and a longer time are needed to inject the arteries of the spinal ganglion than the spinal and radicular ramifications of the same segmental vessel. If analogy drawn from other, better known parts of the nervous system is permissible, the arterial supply of the spinal ganglia may be considered to be rather vulnerable. There may be some relation between this fact and the frequent occurrence of cellular loss in the spinal ganglia, reduction in the number of posterior root fibres and mild degeneration of the posterior column in an otherwise normal spinal cord after the third decade of life, a concept which is further substantiated by the gradual reduction of sensibility, most readily discernible as a reduction of vibratory sense, from the third decade of life on. (R.M.S.)

Pathology of Amyotrophic Lateral Sclerosis.-In five cases of amyotrophic lateral sclerosis measurements showed that most of the large nerve fibres in the ventral
No. 5.

\section{November 1941.}

spinal roots had disappeared, whereas the small fibres appeared normal. The large ventral horn nerve cells suffered a similar fate, the small cells remaining relatively normal. Accurate measurements of the corticospinal tract fibres were made impossible by glial tissue, but it appeared that here the large fibres also suffered the greater damage. All posterior spinal roots appeared normal. In two cases in which bilateral degeneration of the pyramidal tracts was marked muscular hypertonus was not noted, the deep reflexes were normal or hypoactive and extensor plantar responses were absent. In these cases the large fibres in the ventral roots were more extensively damaged than in any of the other cases. It might be inferred from this observation that signs of degeneration of the pyramidal tracts are dependent for their production on the large ventral root fibres. (R. M.S.)

Diseases of Muscle.-A valuable contribution to the study of the effects of prostigmine with a discussion of the factors limiting the use of this drug in the treatment of myasthenia gravis. (R. M. S.)

Neurologic Symptoms following Occlusion of Internal Carotid Artery.-Occlusion of the carotid artery produces atrophy of the optic nerve and loss of vision in the eye on the same side, due to closure of the ophthalmic artery. The circulation is also impaired in the anterior choroidal, anterior cerebral and middle cerebral arteries, which are terminal branches of the internal carotid artery. There may occur softening of the brain, which is usually maximal in the field of the middle cerebral artery. Temporal hemianopia, due to involvement of the optic radiation, may be present in the visual field of the opposite eye. Contralateral hemiplegia and hemianesthesia, more marked in the face and arm than in the leg, also result; they appear to be due to cortical destruction rather than to injury to the internal capsule. If the left cortex is involved in a right-handed person, there may be a variable degree of aphasia. Dysarthria and dysphagia are often present during the first few days after the vascular occlusion, but disappear later. (R. M. S.)

Treatment of Cystic Craniopharyngioma by Intra-Ventricular Drainage.-A new 
method of treating craniobuccal cysts, characterized as intra-ventricular drainage, is here described. The basic principle consists of establishing a communication between the dome of the cyst and the floor of the lateral ventricle. (R. M. S.)

Bony Changes in Pseudohypertrophic Muscular Dystrophy.-The older view that muscular dystrophy is a disease which involves muscle only may have to be revised to include the concept of a more generalized pathological process. In addition to the alterations in creatinine and carbohydrate metabolism and the possible disturbance of the endocrine glands, there is involvement of bone, as indicated by the authors' roentgenographic studies. It is the authors' opinion that the changes cannot be explained on the basis of disuse alone, but may be an expression of a mesodermal defect, resulting in muscular and skeletal defects. (R. M. S.)

Topical Arrangement within Spinothalamic Tract.-The course and localization of the spinothalamic tract were traced in 11 monkeys after anterolateral chordotomies and midline posteroanterior myelotomies had been performed at different levels of the spinal cord. In general, as higher levels in the spinal cord are reached, fibres from lower segments tend to become concentrated laterally and dorsally within the anterolateral column, and fibres from higher level s are situated more medially and inferiorly although there is no absolute segregation at any level. Within the medulla, fibres from the lower levels are concentrated at the periphery of the bulb, whereas fibres from the cervical region lie medially. Although there is evidence that such an arrangement exists, the topical localization of the fibres in the pons, the midbrain or within the nucleus ventralis posterior of the thalamus could not be demonstrated by the methods used in this investigation. (R. M. S.)

Removal of Tumour arising Anterior to Medulla.-There is reported a second case of apparently complete, successful removal of a meningioma which arose from the anterior rim of the foramen magnum and which had displaced the medulla and spinal cord backward. (R. M. S.)

\section{BRAIN}

Vol. 64.

Phantom Limbs and Body Shape. G. Riddoch. 197.

Cerebral Electrical Changes in Experimental Concussion. D. Williams and D. Denny-Brown. 223.

The Component Reflexes of Micturition in the Cat. Part III. F. J. F. Barrington. 239.

Visual Disorientation with Special Reference to
No. 4.

December 1941.

Lesions of the Right Cerebral Hemisphere. W. R. Brain. 244.

Akinetic Mutism with an Epidermoid Cyst of the 3rd Ventricle. H. Cairns, R. C. Oldfield, J. B. Pennybacker, and D. Whitteridge. 273.

A Note on the Clinical Anatomy of the Veins, with Special Reference to the Spinal Veins. H. A. Harris. 291.

No. 1.

March 1942.

*Structure of the Neurohypophysis with Special Reference to Nerve Endings. E. Vazquez-Lopez. 1 .

*The Systemic Nervous Affinity of Triorthocresyl Phosphate (Jamaica Ginger Palsy). C. D. Aring.

*The Anatomy and Physiology of Cutaneous Sensibility: A Critical Review. F. M. R. Walshe. 48.

Neurohypophysis and Nerve Endings.Histological examination of the pars nervosa of the horse pituitary has been made after silver or gold impregnation. In contrast to previous work the whole structure has been studied as a functional entity, fibrous tissue, blood vessels, neuroglia, nerve fibres and all bodies being examined in relation to each other, with a view to assessing their function. It seemed that the very large number of nerve endings of sensory pattern were so arranged that they formed a perivascular receptive apparatus. This lead to the conclusion that the nerves of the pars nervosa are mainly centripetal conductors, and that the pars nervosa is primarily a sensory organ. There was no evidence that it is a specific gland of internal secretion, but rather it constitutes a chemo-receptive or presso- 
evidences that the central parenchymal changes were secondary are less convincing. (D. W.)

Cutaneous Sensibility.-This review includes a full statement and critical analysis of the clinical experimental observations, with sections on Head and Rivers' theory of the afferent nervous system, Trotter and Davies' observations in cutaneous sensi- bility, and Borings' experiment on nerve division. It then deals with the electrophysiological study of sensory function and the anatomy of cutaneous sensibility. The problems of cutaneous pain and tactile sensibility and of the validity of Lewis's hypothesis of a nocifensor mechanism are dealt with in the light of present anatomical knowledge. (D. W.)

\section{JOURNAL OF CLINICAL INVESTIGATION}

\section{Vol. 20.}

The Cause of Death in Experimental Anuria. H. E. Hoff, P. K. Smith, and A. W. Winkler. 607

The Thiamin Content of Human Blood and Urine as determined by the Fermentation Method. R. Goodhart. 625 .

Note on the Interpretation of Clearance Methods in the Diseased Kidney. H. W. Smith. 631.

Effective Renal Blood Flow in Subjects with Essential Hypertension. H. Chasis and J. Redish. 655.

An Epidemic of Influenza. Results of Prophylactic Inoculation of a Complex Influenza A-Distemper Vaccine. J. W. Brown. M. D. Eaton, G. Meiklejohn, J. B. Lagen, and W. J. Kerr. 663 .

Circulatory Failure in Acute Infections. R V. Ebert, and E. A. Stead. 671

Studies on Intrapulmonary Mixture of Gases. IV. The Significance of the Pulmonary Emptying Rate and a Simplified Open Circuit Measurement of Residual Air. A. Cournand, E. De F. Baldwin, R. C. Darling, and D. W. Richards. 681.

A Comparison between Dehydration from Salt Loss and from Water Deprivation. J. W. Nadal, S. and from Water Deprivation. J. W.

Calculation of the Venous-Arterial Shunt in Congenital Heart Disease. M. Prinzmetal. 705.
No. 6.

November 1941.

The Plasma Levels of Vitamin A after the Ingestion of Standard Doses: Studies in Normal Subjects and Patients with Cirrhosis of the Liver. E. P. Ralli, E. Bauman, and L. B. Roberts. 709 .

The Hemodynamic Effects of Angiotonin in Normal Man. S. E. Bradley and B. Parker. 715.

The Nature of the Arterial Hypertension produced in Normal Subjects by the Administration of Angiotonin. R. A. Wilkins and C. N. Duncan. 721.

Some Properties of Human Fetal and Maternal Blood. R. C. Darling, C. A. Smith, E. Asmussen, and F. M. Cohen. 739.

Metabolic Studies in Patients with Cancer of the Gastro-Intestinal Tract. I. Plasma Vitamin A Levels in Patients with Malignant Neoplastic Disease, particularly of the Gastro-Intestinal Tract. J. C. Abels, A. T. Gorham, G. T. Pack, and C. P. Rhoads. 749 .

Fractionation of Serum Proteins in Hyperproteinemia, with Special Reference to Multiple Myeloma. A. B. Gutman, D. H. Moore, E. B. Gutman, V. McClellan, and E. A. Kabat. 865.
Vol. 21.

The Cardio-circulatory Effects in Man of Neosyneph, in (1- $a$-hyd, oxy- $\beta$-methylamino-3-hydroxyethylbenzene hydrochloride). A. Keys and A. ethylbenzene

The Cardio-circulatory Effects in Man of Synephrin Tartrate (d1- $a$-hydroxy- $\beta$-methylamino-4-hydroxyethylbenzene rydrochloride). A. Keys and A. Violante. 13.

The Changes in the Blood Pressure and in the Renal Blood Flow and Glomerular Filtration Rate of Hypertensive Patients following Unilateral Nephrectomy, M. Friedman, A. Selzer, H. Kreutzmann, rectomy. M. Friedman,

Radioactive Iodine as an Indicator in Thyroid Physiology: IV. The Metabolism of Iodine in Graves' Disease. S. Hertz, A. Roberts, and W. T. Salter. 25

Radioactive Iodine as an Indicator in Thyroid Physiology: V. The Use of Radioactive Iodine in the Differential Diagnosis of Two Types of Graves' Disease. S. Hertz and A. Roberts. 31.

The Rôle of the Adrenal Cortex in Acute Anoxia. R. A. Lewis, G. W. Thorn, G. F. Koepf, and S. S. Dorrance. 33.

Effects of Interrupting and Restoring the Circulation to the Lower Extremities. D. Dauber, M. Landowne, L. N. Katz, and H. Weinberg. 47.

The Filtration Rate, Effective Renal Blood Flow, Tubular Excretory Mass and Phenol Red Clearance in Normal Pregnancy. C. A. Welsh, I. Wellen, and H. C. Taylor, Jr. 57.

The Filtration Rate, Effective Renal Blood Flow, Tubular Excretory Mass and Phenol Red Clearance Tubular Excretory Mass and Phenol Red Clearance in Specific Toxemia of Pregnancy.

*The Prevention of Senso:y Neuron Degeneration *The Prevention of Senso oy Neuron Degeneration Various Liver Fractions. M. M. Wintrobe, C. Mufatt. J. L. Miller, Jr., L. C. Kolb, H. J. Stein, and $\mathrm{H}$. Lisco. 71 .
No. 1.

\section{January 1942.}

*Pathological Variations in Blood and Spinal Fluid Pyruvic Acid. E. Bueding, H. Wortis, and M. Stern. 85.

The Significance of Porphynuria in Lead Poisoning. R. Kark and A. P. Meiklejohn. 91 .

The Acid-Base Balance of Premature Infants. W. S Branning. 101.

Renal Function in Patients with Addison's Disease and in Patients with Adrenal Insufficiency Secondary to Pituitary Pan-hypofunction. J. H. Talbott, L. J. Pecora, R. S. Melville, and W. V. Consolazio. 107.

Sensory Neuron Degeneration.-Abnormal gait and sensory neuron degenerative changes in pigs produced by factors deficient in the diet other than thiamin, riboflavin and nicotinic acid were prevented when dessicated whole liver or brewer's yeast were fed. The various fractions obtained in manufacture of anti-pernicious anæmia extract were also tested for protection, and that used in the treatment of pernicious anæmia was most effective when given orally in large doses. (J. N. C.)

Variations in Blood and Spinal Fluid Pyruvic Acid.-Fasting pyruvic acid levels in blood and c.s.f. were examined and variation from the normal was found in " acute" peripheral neuropathy and in most of the cases associated with hyperpyrexia. (J. N. C.) 
Vol. 21.

Studies on the Influence of Vitamin A and Vitamin C on Certain Immunological Reactions in Man. Francis, Jr. 121 .

The Influence of Diet on the Ascorbic Acid Requirement of Premature Infants. M. Dann. 139.

Bleeding Time, Lymph Time, and Clot Resistance in Men. A. L. Copley and J. J. Lalich. 145.

The Significance of the D:N Ratio and its Bearing on the Mechanism of Diabetes Mellitus. D. R. on the Mry. 153 .

The Measurement and Metabolism of Thiamin and of a Pyrimidine Stimulating Yeast Fermentation found in the Blood Cells and Urine of Normal Individuals. A. T. Gorham, J. C. Abels, A. L. Robins, and C. P. Rhoads. 161

The Measurement and Metabolism of Thiamin and of a Pyrimidine Stimulating Yeast Fermentation found in the Blood Cells and Urine of Patients with Leukemia. J. C. Abels, A. T. Gorham, L. Craver, and C. P. R hoads. 177 .

Further Studies on Increased Susceptibility to
No. 2.

March 1942.

Chloroform Poisoning produced in the Albino Rat by Injection of Crystalline Thyroxin. M. A. McIver and E. A. Winter. 191.

The Effects of Large Intravenous Infusions on Body Fluid. J. D. Stewart and G. M. Rourke. 197.

Intravenous Magnesium Sulfate in the Treatment of Nephritic Convulsions in Adults. A. W. Winkler, P. K. Smith, and H. E. Hoff. 207.

The Serological Typing of Hemolytic Streptococci of the Lancefield Group A. L. A. Rantz. 217.

Cardiac Output, Blood and Interstitial Fluid Volumes, Total Circulating Serum Protein, and Kidney Function during Cardiac Failure and after Improvement. W. B. Seymour, W. H. Pritchard, L. P. Longley, and J. M. Hayman, Jr. 229.

The Effect of Foreign Surfaces on Blood Coagulation. E. L. Lozner and F. H. L. Taylor. 241.

The Urinary Excretion of Thiamine as an Index of the Nutritional Level: Assessment of the Value of a Test Dose. H. L. Mason and R. D. Williams. 247.

\section{JOURNAL OF COMPARATIVE NEUROLOGY}

$$
\text { Vol. } 74 .
$$

The Cerebral Cortex of the Penguin. E. H. Craigie. 353.

The Connections of the Basal Optic Root (Posterior Accessory Optic Tract) and its Nucleus in Various Mammals. L. A. Gillilan. 367.

Cerebral Cortical Stimulation of Goats, Normal and Nervous. S. L. Clark, J. W. Ward, and I. S. Dribben. 409.

\section{Vol. 75.}

The Effect of Crossing Nerves to Antagonistic Muscles in the Hind Limb of the Rat. R. W. Sperry. 1. Some Reflex Effects of Nerve Crossing and Nerve Regeneration. W. G. Watrous and J. M. D. Regeneration.

The Development of the Nervus Terminalis in Man. A. A. Pearson. 39.

Thalamo-Cortical Connections of the Rat's Brain. K. S. Lashley. 67.

\section{Vol. 75.}

The De velopment of the Olfactory Nerve in Man. A. A. Pearson. 199.

Adrenal Innervation. W. E. MacFarland and H. A. Davenport. 219.

The Ratio of Preganglionic Neurons to Postganglionic Neurons in the Visceral Nervous System. G. A. Wolf. 235

The Growth of Ependyma. R. Altschul. 245 .
No. 3.

Further Studies in Naso-Genital Relationship. Anatomical Studies of the Peri-Hypophyseal Region in the Rat. L. R. Zacharias. 421.

Development of the Afferent Components of the Facial, Glosso-pharyngeal and Vagus Nerves in the Rabbit Embryo. D. L. Kimmel. 447.

Development of the Optic Nerves of Amblystoma. C. J. Herrick. 473.

No. 1.

August 1941.

The Vascular Pattern in the Central Nervous System of the Monotremes and Australian Marsupials. S. Sunderland. 123.

Structure of the Area Striata of the Cat. J. L. O'Leary. 131.

The Early Development of the Fascicular Longitudinals Medialis and Associated Secondary Neurons in the Rat, Cat and Man. R. Hhines and W. F. Windle. 165.

No. 2.

October 1941.

The Eyes and Optic Paths of the Catfish, Ameiurus. C. J. Herrick. 255.

On Encephalometry. A Preliminary Study of the Brain of Man, Chimpanzee and Macaque. G. von Bonin. 287.

The Ansoparamedian Lobule of the Cerebellum and its Correlation with the Limb-Muscle Masses. O. Larsell and S. von Berthelsdorf. 315.

Spinal Autonomic Outflows in Man and Monkey. D. Sheehan. 341 .

No. 3.

December 1941

The Diencephalon of the Coney, Hyrax Syriaca. M. Ibrahim and W. M. Shanklin. 427.

Optic and Postoptic Systems of Fibres in the Brain of Necturus. C. J. Herrick. 487.

of Age Correlated with Functional Capability. I. D. Hogg. 371.

The Mammillary Peduncle and Ventral Tegmental Nucleus in the Cat. C. A. Fox. 411.

\section{JOURNAL OF MENTAL SCIENCE}

Vol. 88 .

Hyperthyrotic Catatonia: A Schizophrenic SymptomComplex. R. E. Hemphill. 1.

The Prognisucic Factors of Adolescent Psychoses. A. Barham Carter. 31 .

Observations in Hypoglycæmia. III. C.S.F. Sugar and Coma. W. Mayer-Gross. 82.

The Treatment of Tuberculosis in Unco-operative Patients. A. Kennedy. 89.
No. 370.

January 1942.

Electro-encephalography in Cases of Mental Disorder. W. G. Walter. 110.

Further Observations on Sodium Amytal Experiments. F. Reitmann. 122.

Blood Amines. D. Richter and M. Lee. 127.

Three Ganser States and Hamlet. E. S. Stern and W. H. Whiles. 134 . 
Vol. 88.

The Investigation of Personality in Patients treated by Prefrontal Leucotomy. E. L. Hutton. 275. Some Preliminary Remarks on Prefrontal Leucotomy. G. W. T. H. Fleming. 282

Forms of Behaviour of the Electrical Resistance of the Skin related to Certain Psychiatric and Endocrine Conditions. H. E. Hemphill. 285.

The Measurement of Body Resistance by Bridge Methods. W. Grey Walter. 306.
No. 371.

April 1942.

Auxiliary Genes for Determining Sex as Contributory Causes of Mental Illness. L. S. Penrose. 308.

The Measurement of Dementia. M. B. Brody. 317. Psychiatric Syndromes following Blast. E. W. Anderson. 328.

Arhinencephaly with Incomplete Separation of the Cerebral Hemispheres. G. W. T. H. Fleming and R. M. Norman. 314 .

\section{JOURNAL OF NERVOUS AND MENTAL DISEASE}

Vol. 94.

Acute Demyelinizing Processes in the Nervous System. A. J. E. Akelaitis and P. H. Garvey. 405.

Félix Vicq D'Azyr and Benjamin Franklin. R. Spillman. 428.

Huntington's Chorea. H. G. Hadley. 445.
No. 4.

October 1942.

Toxic Psychosis Due to Thiocyanate. M. R. Plesset. 447 .

Intracranial Lesions as a Cause of Sudden Death. E. V. Swift, and F. P. Moersch. 452.

A Rorschach Study of Psychotic Personality in Uniovular Twins. G. W. Kisker and N. Michael. 461 .
Vol. 94

Two Cases of Myelodysplasia. A. Austregesilo and A. R. de Mello. 529 .

A Case of Puerperal Psychosis recovering from Four Attacks. H. G. Hadley. 540

A Study of Migraine. C. T. Gayley. 542.

Complications and Unusual Phenomena arising in the Course of Metrazol Treatment of the Psychoses
No. 5.

November 1941

-Their Classification and Management. J. Epstein. 562.

Angioma Simplex of the Pons. K. T. Neubuerger and W. L. Silcott. 586.

Recent Progress in Psychosomatic Medicine. J. Notkin. 593.
Vol. 94.

Monstrosity due to Intrauterine Purulent MeningoEncephalitis. H. N. Roback and H. F. Kahler. 669.

The Challenge of Social Neuroses. W. Eliasberg.

Pneumographic Patterns during Convulsive Therapy of Schizophrenia. E. Friedman and H. Barry. 688 . The Narcoleptic-Cataplectic Syndrome and its
No. 6.

December 1941.

Accompanying Mental States. S. Brock and B. Weisel. 700.

Family Periodic Paralysis associated with Exophthalmic Goiter. A. G. Hildebrand and E. J. Kepler. 713

Epilepsy and Suicide. C. Prudhomme. 722.

Hallucinosis as a Clinical Entity and its Interpretation. A. Gordon. 732 .

\section{JOURNAL OF NEUROPATHOLOGY AND PSYCHIATRY, LENINGRAD}

\section{Vol. 9.}

Tentative Treatment of Atypical and Delayed Alcoholic Psychoses by Hypoglycæmia. Malkin and Yankowsky. 3.

Hepato-Lenticular Degeneration. Konovalov. 12.

Psychic Changes in the Initial Stages of Chronic Mercurial Intoxication. Semenova. 22.

Vegeto-Animal Syndrome in Catatonia. Convulsive Therapy and Dynamics of Chronic Schizophrenia. Karashkevish. 30

Influence of Shock Therapy on Chronic Schizophrenia. Moskin. 38

Polyganglio Radiculitis. Luria. 45.
No. 10.

1940.

Leydon-Westphal Syndrome in Malaria. Malkich. 51

Traumatic Ophthalmoplegia. Smynov. 55. Facial Diplegia in Cranial Injury. Benkovich. 58. Meningococcal Septicæmia. Strachovich. 62.

Intradermal Therapy and its Mechanism. Birbrayer. 64

Foreign Bodies in Gastro-Intestinal Tract in the Insane. Smirnov and Gurstev. 65.

Disturbance of Sleep with Bulimia and Polydipsia. Footer. 68.
Vol. 9.

Bilateral Injury of Parietal Cortex. Golandt. 3. Complex Tactile Kinetic Hallucination (Stereognostic). Ravkin. 14

Reduced Orientation. Chlenro and Shubert. 25

Pathological Anatomy of Encephalitis B. Chenisheo and Lukonsky. 30.

Influenzal Psychoses. Yankovsky. 43

Psychic Changes in Brucellosis. Jekoboo. 49

Psychogenesis in Early Childhood. Blay. 56.
No. 12.

1940.

Organization of Dispensary Psychiatric-legal Investigations. 62 .

Action of Morphic Preparations. 68.

Treatment of Endogenous Depressions with Cortin. Korolook. 75.

Treatment of Schizophrenia. Ovchavenko. 78

Basic Changes in Subdural Insufflation of $\mathrm{N}_{2} \mathrm{O}$ and $\mathrm{O}_{2} .81$. 
Vol. 10.

Founders of Moscow School of Neuropathologists. 3.

Pathogenesis of Epilepsy. Sep. 9.

Theory of Treatment of Schizophrenia. Gurevich. 17.

Convulsive Therapy. Deterof. Magnitzky and Hahativian. 21.

Structure of Psychosis in Insulin Therapy. Zalmarson. 39.

No. 1.

1941.

Results of Insulin Therapy, 1937-40. Molokov 44.

Achievements of Soviet Neuropathology. Horoshleo. 52.

Basic Organization in Psychiatric Dispensaries. Karanovich. 57.

Vitamins and the Nervous System. Bron. 67.

Vol. 10.

Role of Vegetative Nervous System in Physiological and Pathological Processes. Proppu-Grashchenko. 5.

Residual Phenomena in Parameningo Encephalitis in the Young. Geyon. 15.

AC. Encephalitis. Perviskin. 21.

Neurological Symptoms in Chronic Sinusitis. Chodoc. 28.

On Anterior External Arcuati and Intra-pyrámidal Arcuati Fibres. Fayzoolajer. 41.

Clinical Features of Cerebrál Ėmbolism in Organic Heart Disease. Mukeer. 45.

Similarities and Differences in Visual and Auditory Cortex. Blinkov. 48.

Aclinomycosi of Cerebrum. Vizen. 53.

Aclinomycosi of Cerebrum. Vizen. 53. Neuralgias. Applications in 55

Syndrome Unilateral Paralysis, Numerous Cranial Nerves. Hazanov. 59.

Malarial Cerebrospinal Meningitis. Malkiel. 61 .

On Unequal Pupils. Smirnov. 64

Cerebral Injury. Duchinsky, 68.

Diencephalic Epilepsy and its Treatment. Veinberg. 72.

Epilepsy as a Reflex to Physiological Irritation. Yesclavich. 74

Prevention of Contractures in Nervous Affections of the Central Nervous System. Shiform and Horavkin. 76

Vol. 10.

Work of Professor Osipov. Zuzin. 3.

Genesis of Affective States. Osipov. 7

Carriers and Reservoirs in Virus of Encephalitis. Pavlovski. 10

Therapy of Nervous Diseases. Davidenko. 12.

Diencephalopathic Psychoses of Periodicity. Golant. 18 phalopathic Psychoses of Periodicity. Golant.

18.
Ontogenesis of Vegetative Centres in Humans. Piness. 24.

Character of Berger Rhythm in Normal and Pathological Cases. Sarkisov and Livranov. 28.

Influence of Cerebellum and Cerebrum on the

Vegetative Functions. Asrotyn. 35.

Traumatic Epilepsy. Omorokov. 39.

Re-establishment of Suppressed Functions. Vasiliev. 44 .
No. 2.

1941.

Certain Pathological Changes in Nervous System in Hydrophobia. Uspensky. 79.

Mitogenic Rays in C.S.F. in Affections of Nervous System. Lotzman. $\cdot 81$.

Complications of Epidemic Meningitis in Children. Shirokov. 84

Case of Relapsing Myelitis Gravidarum Toxica. .

Three Cases of Affections of the Nervous System by Lightning. Shendetovich. 86

Treatment of Injury of Spinal Cord. Karaev and Fooki. 89.

Catheterization of the Sylvian Aqueduct. Yoselevich. 90.

Amyostatic Symptom-complex in a Case of Kayser Fleisher Ring occurring in Familial Disease simulating Banti's Disease. Shternberg. 92.

Extrapyramidal Symptoms in Tumours of the Extrapyramidal Symptoms in Tumous

Cerebello-pontine Angle. Litvak.
Supracellar Tumours. Mazilo. 96.

Magnesium and Calcium in the Cerebrospinal Fluid and in Blood Serum in Nervous Diseases. Pleshchitser. 98.

Radiological Investigations of the Cardiovascular and Respiratory Systems in the Insane. Kosliki and Goldberg

Quiet as a Therapeutic Agent in Noisy Patients. Decentralization of Psychiatric Help. Berger. 105.

No. 3 ,

1941.

Individual Differences in Sensitiveness. Aranyev. 49.

Theory of Hallucinations. Rorchevsky. 53.

Histopathology of Hepato Lenticular Degeneration Konovalov. 59.

Non-specific Therapy in Epidemic Cerebrospinal Meningitis. Alexandrov. 67.

Nervous Syndrome in Infectious "Nephrosis." Shapoval. 70.

Spring-Summer Encephalitis. 1939. Arbuzov. 73. Alternative Clonus of Big Toe. Lichtenstein. 77.

High Frequency Currents in Affections of the Peripheral Nerves. Kovda. 82.

Research on Chronaxie in Demyelinated Nerves. Ignatov and Feldman. 88.

\section{JOURNAL OF NEUROPHYSIOLOGY}

\section{Vol. 4.}

Cerebral Blood Flow and $p \mathbf{H}$ in Excessive Cortical Discharge induced by Metrazol and Electrical Stimulation. H. Jasper and T. C. Erickson. 333. Relation between Electrical Changes during Nerve Activity and Concentration of Choline Esterase. D. Nachmansohn and B. Meyerhof. 348 .

*Nature of the "Endplate Potential" in Curarized Muscle. J. C. Eccles, B. Katz, and S. W. Kuffler.

*Isolation of Intrinsic and Motor Mechanism of the Monkey's Spinal Cord. S. Tower, D. Bodian, and $\mathrm{H}$. Howe. 388.

*Fibrillation in Skeletal Musel in Relation to Denervation and to Inactivation without Denervation. S. Tower, H. Howe, and D. Bodian. 398.
No. 5.

July 1941.

*Initiation of Muscle Impulses at Neuro-Muscular Junction. J. C. Eccles and S. W. Kuffler. 402.

The Human Electro-Corticogram. J. E. Scarff and W. E. Rahm. 418.

Cerebral Blood Flow and $p \mathbf{H}$ in Cortical Discharge.-Local increased acidity of the cortex resulting from neuronal discharge causes a vascular dilatation which tends to maintain a constant $p \mathrm{H}$. Thus relative acidity caused by a metrazol discharge is followed by a relative alkalinity as blood flow is increased. It is suggested that small 
alkaline waves concomitant with onset of facilitation Imay be due to DC voltage components of the cortical electrogram in a violent metrazol discharge. The features of the metrazol discharge are not altered by variations in $p \mathrm{H}$ of the cortex between 7.0 and 7.5 induced by hyperventilation, $\mathrm{CO}_{2}$ and injection of acid or alkaline solutions into the blood stream. After discharge induced by contralateral cortical impulses shows local cortical $p \mathrm{H}$ and blood flow changes similar to those of a metrazol discharge. It is concluded that increase in $p \mathrm{H}$ is a result of vascular reaction to increased neuronal activity and is not important in facilitation processes. (W. M. H.)

" Endplate Potential." - The endplate potential (e.p.p.) set up by a nerve volley at the region of the myoneural junction is shown to be a local depolarization of the muscle fibres acting like a local catelectrotonic potential produced by a subthreshold electric stimulus. It spreads a short distance along the muscle fibres with considerable decrement and progressive slowing. The time course of its waning phase is little altered by heat in contrast with the rising phase. In the frog a second nerve volley sets up an e.p.p. which is 80-100 per cent. larger than the first. Muscle spikes are initiated when e.p.p. reaches a certain critical level. Neuromuscular facilitation occurs when the required level is reached by summation of successive e.p.p.'s. (W. M. H.)

Isolation of Intrinsic Mechanism of Spinal Cord.--In two monkeys a study was made of the lumbo-sacral cord 10-14 days after complete transection at the last thoracic segment, and section of all the posterior roots. Thus it was possible to view the intrinsic and motor mechanism of the spinal cord cleared of all descending and posterior root fibres. In such a condition the skeletal muscle is wholly inactive. (W. M. H.)

Fibrillation in Skeletal Muscle.-In a preparation such as the preceding fibrillation is observed in leg muscles only if the sciatic nerve is cut. Atrophy developing in conditions of inactivation without denervation may thus properly be considered atrophy of disuse. (W. M. H.)

Initiation of Impulses at Neuro-Muscular Junction.-The rising phase of the muscle action potential set up at a focus of endplates by a nerve volley is shown to have a component due to endplate potential (e.p.p.), the initial step of the potential of normal muscle allowing of matching by the e.p.p. seen in curarized muscle. Simple spike and double stop types of action potential differ only in the time of the spike origin relative to the e.p.p. In the latter the spike arises only when the e.p.p. has reached 16 per cent. of the peak potential. Large initial e.p.p.'s (12-18 per cent.) are probably the sole mechanism initiating muscle impulses normally and in sub-paralytic curarization; where initial e.p.p.'s are small an additional excitatory mechanism, possibly nerve action currents, forestalls the excitatory action of the e.p.p. (W. M. H.)

Human Electro-Corticogram.-A compact apparatus is described for the recording of electrical potentials of the brain exposed at operation. Findings in abnormal conditions are given. (W. M. H.)
Vol. 4.

Effect of Chronic Painful Lesions on Dorsal Root Reflexes in Dog. R. Anderson, W. K. Livingston, and R. S. Dow. 427.

* Reflex Activity in the Spinal Extensors. J. S. Denslow and G. H. Clough. 430.

* Steady Potential Fields and Neurone Activity. B. Libet and R. W. Gerard. 438.

*Fatigue and Refractoriness in Nerve. E. T. von

Brücke, M. Early, and A. Forbes. 456.

*Acetylcholine Esterase Concentration during the Development of the Human Fetus. K. A Development of 4.

* Localization of Cerebral Center Activating HeatLoss Mechanisms in Monkeys. L. E. Beaton, W. A. McKinley, C. M. Berry, and S. R. Ranson. 478.

*The Endplate Potential during and after the Muscle Spike Potential. J. C. Eccles and S. W. Kuffler. 486.

Reflex Activity in Spinal Extensors.Cases of periarticular disease showing no obvious organic pathology nor voluntary muscle contraction were examined for abnormal muscle activity in the segments of the lesion. Activity in motor units were sometimes found when the subject was at rest. The rate of unit discharge was 3-24 per sec. The origin of these reflex dis-
No. 6.

September 1941.

charges is thought to be in abnormal stresses in joints. (W. M. H.)

Steady Potential Fields and Neurone Activity.-The passage of potential waves through the cerebral hemispheres after neural connections are blocked depends on inter-cellular currents. These are considered to come from a potential from the axonic to dendritic pole of similarly oriented neurones. Inter-cellular currents may be of importance in the synchronizing of neurones and the mass functioning of the cortex. Steady potentials between the pial and ventricular surfaces of the frog's brain, caffeine potential waves and the effect of depolarization at points in the hemisphere are here described. (W. M. H.)

Fatigue and Refractoriness in Nerve.The effect of prolonged repetitive stimulation of medullated nerve is to delay recovery of responsiveness (size of maximal response) in the relative refractory phase and, to a greater extent, recovery of 
excitability. Excitability is reduced much more in the unconditioned (resting) than in the conditioned (refractory) nerve. Separate refractory states after two impulses are shown to sum in the same way as subnormality. Subnormality, the relatively slow recovery of excitability, is regarded as a continuation of the relative refractory state, during which responsiveness is recovered. (W. M. H.)

Acetylcholine Esterase Concentration during Human Fetus Development.-The periods of increase of choline esterase in the various parts of the nervous system of the human fœtus follows the order of their morphological differentiation (midbrain and medulla, spinal cord, diencephalon, basal ganglia, and cerebral hemispheres). The most rapid concentration of the esterase in muscles of the shoulder girdle occurs when motility is developing (about 80 days). (W. M. H.)

Heat-Loss Mechanisms in Monkeys.-
No. 7.

eneucleation of the eyes and occipital lobectomy. Hypomotility is related to lesions of the rostral parts of areas 6 and of area 8 . (W. M. H.)

Spinal Mechanism of Pyramidal System. -Stimulating the pyramidal fibres in the medulla of the cat the authors have studied the working of the spinal interneurons in the relay of pyramidal activity. Small nuclear elements close to the tract are the initial, the cells of the intermediate region the premotoneuron relay. Facilitation of motoneurons as tested through primary afferent volleys parallels activity in the intermediate region. As pyramidal activity is intensified, shortening of the functional path to the motoneurons occurs. Reciprocal innervation is accounted for by inhibition of some interneurons of the intermediate region. Motoneuron discharge from pyramidal activity is highly asynchronous. Spinal reflex reinforcement of pyramidal activity begins with the onset of movement. (W. M. H.)

\section{JOURNAL OF PHYSIOLOGY}

Vol. 100.

The Ratio between Antidiuretic and Pressor Activities of Posterior Pituitary Extract subjected to Mild Hydrolysis. A. M. Fraser. 233.

A Method for Estimating the Fraction of the Volume of a Muscle contained in the Vascular System. J. F. Danielli. 239.

The Volume of the Vascular System, and Penetration of Sugars from the Vascular System into the Intercellular Space. J. F. Danielli and H. Davson. 246 .

An Investigation of Simple Methods for Diagnosing Vitamin A Deficiency by Measurements of Dark Adaptation. D. J. Dow and D. M. Steven. 256.

The Behaviour of the Pregnant Uterus of the Guinea Pig. G. H. Bell. 263 .
No. 3.

November 1941.

A Quantitative Method of Assay for Thrombin and Prothrombin. L. B. Jaques. 274.

*The Latency and Conduction of Potentials in the Spinal Cord of the Frog. Fwu Tarng Dun. 282.

Strength and Size of Bone in Relation to Calcium Intake. G. H. Bell, D. P. Cuthbertson, and J. Orr. 298

*Abortive Impulses at the Neuro-Muscular Junction. J. C. Eccles and W. J. O'Connor. 317.

The Glycogen Content of the Frog's Heart. F. Davies and E. T. B. Francis. 328.

*Observations Bearing on Synaptic Transmission by Acetylcholine in the Spinal Cord. E. Bülbring and J. H. Burn. 336. 
Latency and Conduction of Spinal Cord Potentials.-When a volley of sensory impulses is sent into the spinal cord potential changes may be detected in the ipsilateral and some contralateral dorsal roots. The latency of this dorsal root potential increases with the distance between the roots of stimulation and observation. It does not vary with change in the intensity of stimulation. The potential seems to depend on the integrity of the dorsal columns and is conducted at $1-2 \mathrm{~m} . / \mathrm{sec}$. The potential is considered to arise presynaptically and excitation of secondary neurones to occur during its rising phase. (W. M. H.

Abortive Impulses at Neuro-Muscular Junction.-At the endplate region of cats' solens abortive impulses spreading less than $1 \mathrm{~mm}$. are observed on curarization in the refractory state of neuro-muscular transmission. It is shown that the endplate potential set up in normal muscle by an early second volley is diminished to one-third by refractoriness. With increasing volley interval the action potential of the second becomes steeper and greater till an inflexion on the rising phase shows the spike due to a fully propagated muscle impulse. With longer volley intervals the spike origin encroaches progressively earlier on the e.p.p. These observations on the role of e.p.p. in the rising phase of the action potential necessitate a revision of earlier views. (W. M. H.)

Synaptic Transmission by Acetylcholine.Acetylcholine injected into the cord circulation in the dog has a transient depressant effect on the knee jerk. It augments the flexor reflex slightly. Eserine, prostigmine, and nicotine all depress the knee jerk and augment the flexor reflex. After eserine and prostigmine acetylcholine depresses or abolishes the knee jerk. After eserine the inhibition of the knee jerk caused by stimulation of the posterior tibial nerve is followed by an exaggerated rebound. The effects of acetylcholine are considered to resemble those of posterior tibial nerve stimulation, both before and after eserine. After stimulation of the central end of the cut sciatic nerve acetylcholine is found in the venous effluent from the cord if Ringer's solution containing eserine be used. Adrenaline facilitates the discharge of impulses from the spinal cord following the injection of acetylcholine. (W. M. H.)

\section{Vol. 100.}

A Note on Interaction between Nerve Fibres. B. Katz and O. H. Schmitt. 369 .

The Assimilation of Radio-active Phosphorus Deficiency in Rats. W. E. Gaunt, H. D. Griffith, and J. T. Irving. 372.

Glycogen and Adipose Tissue. E. Tuerkischer and E Wertheimer. 385.

Ovulation in the Rabbit after Destruction of the Greater Superficial Petrosal Nerves. M. Vogt. 410.

The Action of Curare on the Respiratory Centre. J. Fegler. 417.

The Influence of a Deficiency of Vitamin $B_{1}$ and of Riboflavin on the Reproduction of the Rat. $K$. $H$. Coward B. G. E. Morgan and L. Waller. 423.

Urea Formation in the Isolated Perfused Liver of the Urea Formation in the Isolated
Rat. O. A. Trowell. 432 .

Olfactory Reactions in the Brain of the Hedgehog. E. D. Adrian. 459.

* Observations on the Properties of S-methyl IsoThiourea Sulphate, with Particular Reference to the Circulatory Effects. M. McGeorge, M. Sherif, and F. H. Smirk. 474.

Olfactory Reactions in Brain.-In the hedgehog electrical activity in the olfactory bulb and olfactory area of the brain has been studied in nembutal and chloralose anæsthesia. Normal breathing produces at each inspiration a regular series of large potential waves of frequency about $15 \mathrm{p}$. sec. Forcible sucking of air through the snout
No. 4

March 1942.

increases the frequency to $45 \mathrm{p}$. sec. Small irregular waves replace these regular waves when a distinct odour is added to the air. It is suggested that the olfactory organ may be stimulated mechanically by the air current as well as chemically by the odours in it, and that different chemical stimuli produce different distributions of excitation and so different patterns in the brain. (W. M. H.)

Circulatory Effects with S-Methyl IsoThiourea Sulphate.-In the anæsthetized decerebrate and pithed animal S-methyl iso-thiourea sulphate produces a considerable and prolonged rise in blood pressure, accompanied by some slowing of the heart. The rise in B.P. is found after blocking of sympathetic motor nerve endings by either ergotamine or F 933, and the slowing of the heart is independent of the vagus. Study of the relative effect of like concentrations in the whole animal and isolated heart indicates that the substance undergoes a change in composition in the whole animal. (W. M. H.)

\section{PHYSIOLOGICAL REVIEWS}

Vol. 21

Endocrines in Invertebrates. B. Scharrer. 383. Organic Acid-Soluble Phosphorus Compounds of the B. G. Guest and S. Rapaport. 410. The Nutrition of the Fetus. A. St. C. Huggett. 438.
No. 3.

July 1941.

The Circulation of the Bile Acids in Connection with their Production, Conjugation and Excretion. B. Josephson. 463

The Physiology of the Gene. S. Wright. 487. 
Vol. 21.

Factors affecting the Tests of Kidney Function. R. C. Herrin. 529.
No. 4.

October 1941.

Anaphylaxis. C. A. Dragstedt. 563.

Antihormones. K. W. Thompson. 588.

\section{Vol. 22.}

The Insensible Loss of Water. L. H. Newburgh and M. W. Johnston. 1.

Hemoglobinuria. C. L. Yuile. 19.

The Fuel for Muscular Exercise. C. L. Genmill. 32.
No. 1.

January 1942.

Recent Advances in Knowledge of the Liver. C. D. Snyder. 59.

The Present Status of the Shock Problem. C. J. Wiggers. 74.

\section{PSYCHIATRIC QUARTERLY}

\section{Vol. 16.}

The Rorschach Method and Its Uses in Military Psychiatry. J. A. Brussel and K. S. Hitch. 3 . A Comparative Table of the Main Rorschach Symbols. Z. A. Piotrowski. 30.

The Catatonic Death Reaction. P. Milici. 38.

Some Shakespearean Characters in the Light of Present-Day Psychologies. I. S. Wile. 62.

Alzheimer's Disease. W. H. English. 91.

Problems of Cancer Therapy in a State Hospital. J. Moore. 107.

The Validity of the Shipley-Hartford Retreat Test for "Deterioration." B. Pollack. 119.

Juvenile Amaurotic Idiocy. G. A. Jervus, L. Roizin, and W. H. English. 132.
No. 1.

January 1942.

Family Care Placement of State Hospital Patients as a Method of Situational Therapy. K. Stuber as a Method of Situational

Echo of Reading: Impersonal Projection in Schizophrenia. M. C. Meehan. 156.

Ambulatory Insulin Therapy. P. J. Tomlinson and L. D. Ozarin. 167.

Varicella with Encephalitis. S. C. Karlan. 174.

The Incidence of Psychoses and Other Mental Abnormalities in the Families of Recovered and Deteriorated Schizophrenic Patients. O. Kant. Deter.

Adolf Hitler's " My New Order"-A Critical Review. 187.

Vol. 16.

Anxiety in a Neurosis of 70 Years' Standing. C. P. Oberndorf and A. Eisendorfer. 221.

Folie a Deux - the Psychosis of Association. A Gralnick. 230.

Mental Defectiveness with Unusual Syndrome of Congenital Physical Anomalies. S. Androp. 264 Deeper Level of Regression. G. S. Sprague. 272.

Hirsutism. J. H. Schwartz. 281.

Review of the Research Program of the New York State Psychiatric Institute and Hospital for 1941 N. D. C. Lewis. 295.

A 10-Year Comparative Study of the Treatment of General Paresis with Fever Therapy (Radiant Energy) and Chemotherapy. K. K. Slaght and N. Jones. 306.

Preliminary Study of the Art Productions of the Adult Psychotic. J. Zimmerman and L. Garfinkle. 313 .

\section{SCHWEIZER ARCHIV FÜR NEUROLOGIE UND PSYCHIATRIE}

Vol. 48.

L'Amnesia retrograda dopo l'Elettroshock. Contributo allo studio della patogenesi delle amnesie in genere. (Retrograde amnesia in electrically in genere. (Retrograde amnesia in electrically induced convulsions. A contribution to the study
of the pathogenesis of amnesia.) G. Flescher. 1.

Spiegelschrift bei Triebstö rungen. (Mirror-writing in disturbances of instinctive reactions.) K. Heymann. 29.

A propos de la classification des tumeurs cérébrales. (Classification of cerebral tumours.) M. JequierDoge. 40.

Zur Kritik des Typenbegriffes. (A criticism of the doctrine of " types.") R. Meili. 71.

Un cas de polyradiculo-névrite ascendante subaiguë avec dissociation albumino-cytologique. Etude anatomoclinique. (Ascending polyradi;uloncuritis
No. 2.

\section{April 1942.}

Massive Dose Testosterone Therapy in Male Involutional Psychosis. M. Zeifert. 319.

Treatment of Speech Defects in a State Schooi. J. Sirkin and W. F. Lyons. 333.

The Problem of Psychogenic Precipitation in Schizophrenia. O. Kant. 341 .

Asphyxial Episodes and their Prevention in Electric and other Convulsive Therapies. H. Brill and L. Kalinowsky. 351 .

Progressive Lenticular Degeneration. G. A. Jervis, J. Notkin, I. S. Freiman, and J. Moore. 357.

Without Psychosis-Chronic Alcoholism. C. A Whitaker. 373.

Reducing the State Hospital Population. W. A. Thompson. 393.

Experience with Intravenous Use of Solution of Crystalline Zinc-Insulin in the Hypoglycemic Treatment of Schizophrenia. L. Reznikoff and J. J. Scott. 399 . 